\title{
Penetrating atherosclerotic ulcer of the descending thoracic aorta and arch
}

\author{
Kwang Ree Cho, MD ${ }^{\mathrm{a}}$ \\ Anthony W. Stanson, MD \\ D. Donald Potter, MDa \\ Kenneth J. Cherry, MD ${ }^{c}$ \\ Hartzell V. Schaff, MD ${ }^{a}$ \\ Thoralf M. Sundt III, MD
}

From the Departments of Surgery a and Radiology, ${ }^{\mathrm{b}}$ Division of Cardiovascular Surgery, and Department of Surgery, ${ }^{\mathrm{c}}$ Division of Vascular Surgery, Mayo Clinic, Rochester, Minn.

Read at the Eighty-third Annual Meeting of The American Association for Thoracic Surgery, Boston, Mass, May 4-7, 2003.

Received for publication May 2, 2003; revisions requested Sept 27, 2003; accepted for publication Nov 4, 2003.

Address for reprints: Thoralf M. Sundt III, MD, Division of Cardiovascular Surgery, Department of Surgery, Mayo Clinic, 200 First Street SW, Rochester, MN 55901 (Email: Sundt.Thoralf@mayo.edu).

J Thorac Cardiovasc Surg 2004;127: 1393-401

$0022-5223 / \$ 30.00$

Copyright $\odot 2004$ by The American Association for Thoracic Surgery

doi:10.1016/j.jtcvs.2003.11.050
Objective: The clinical behavior of penetrating atherosclerotic ulcers of the aorta is controversial. We reviewed our experience with this entity over a 25 -year interval.

Methods: Cases were identified using the Department of Radiology database searching for the diagnoses of aortic dissection, intramural hematoma, or penetrating ulcer between 1977 and 2002. Available imaging studies were reviewed by a vascular radiologist to confirm the diagnosis of penetrating ulcer and perform serial measurements.

Results: One hundred five patients with penetrating atherosclerotic ulcers of the descending thoracic aorta or arch with $(n=85)$ or without $(n=20)$ associated intramural hematoma were confirmed. Two patients with ulcers in the ascending aorta were excluded. There were 73 men and 32 women with a mean age of $72 \pm$ 9 years. Comorbidities included hypertension in 97 (92\%), tobacco use in $81(77 \%)$, and coronary artery disease in $48(46 \%)$. Of nonoperated patients with follow-up studies, the mean thickness of the intramural hematoma decreased at 1 month in $89 \%$ and completely resolved at 1 year in $85 \%$. There were 3 deaths (4\%) within 30 days among 76 patients treated medically and 6 deaths (21\%) among 29 patients treated surgically $(P<.05)$. Failure of medical therapy defined as surgery or death was predicted by rupture at presentation (odds ratio $=20.6$ ) and era of treatment (before 1990, odds ratio 9.9) but not aortic diameter, ulcer size, or extent of hematoma.

Conclusion: Although careful follow-up is necessary, many penetrating atherosclerotic ulcers of the thoracic aorta can be managed nonoperatively in the acute setting.

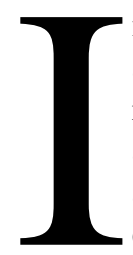

$\mathrm{n}$ recent years subtypes of acute aortic pathology including penetrating atherosclerotic ulcer (PAU) and intramural hematoma (IMH) have been recognized in addition to classic aortic dissection as etiologies of "acute aortic syndromes." ${ }^{1}$ Although these conditions may simply represent variants of dissection, ${ }^{2,3}$ data are accumulating to suggest there may be differences in the clinical behavior of these entities. ${ }^{4-6}$ Accordingly, despite general agreement regarding the natural history of classic aortic dissection and hence the indications for surgical intervention in that condition, debate persists regarding PAU and IMH.

When attention was drawn to PAU by Stanson and associates ${ }^{7}$ in 1986, this entity was thought to have a particularly malignant behavior warranting an aggressive surgical posture. Shortly thereafter, however, Hussain and colleagues ${ }^{8}$ presented convincing evidence that nonoperative management was successful in many cases. More recently others ${ }^{9}$ have supported the original view with data suggesting that PAU is even more malevolent than classic dissection. 


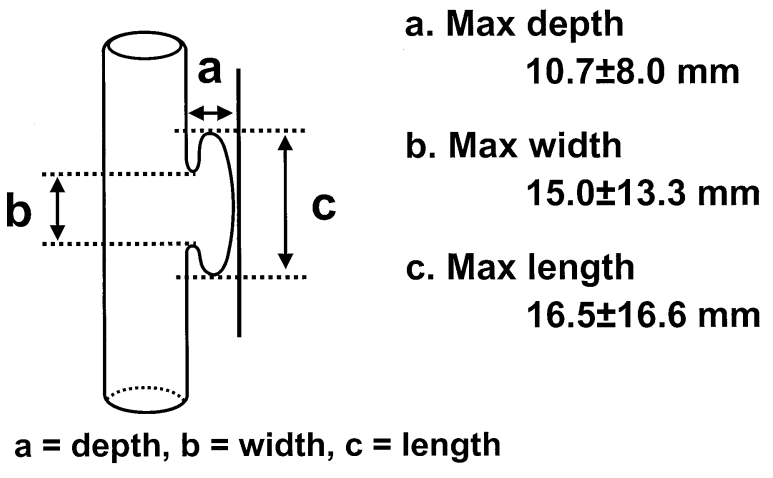

Figure 1. Dimensions of penetrating atherosclerotic ulcers. Ulcer dimensions were determined as shown from all available computerized tomographic scans.

Similar disagreement exists regarding the related entity, IMH. Initial reports supported surgical therapy of IMH involving the ascending aorta (type A) and medical therapy of those confined to the descending aorta (type B). ${ }^{10}$ More recently expectant therapy of type A IMH has been advocated by some ${ }^{4}$ while other investigators counter that both IMH and PAU are "virulent vascular lesions" for which prompt surgical intervention is indicated..$^{11}$ It has also been suggested that the presence of PAU in combination with IMH is particularly ominous. ${ }^{12}$

We have had particular interest in PAU at our center for some time. ${ }^{7}$ Accordingly, we have reviewed our clinical experience over the past 25 years to examine the behavior of PAU with or without associated IMH.

\section{Materials and Methods}

The database of the Department of Diagnostic Radiology was searched for cases with the diagnosis of aortic dissection, IMH, or PAU between July 1977 and August 2002. Of 1064 cases so identified, reports were reviewed and clear cases of aortic dissection without evidence of hematoma or penetrating ulcer were eliminated. Of the remaining 163 patients, available aortograms and computerized tomographic (CT) scans were reviewed by a cardiovascular radiologist (A.W.S.) blinded to clinical course. Of 107 patients found to have penetrating ulcers of the thoracic aorta, 2 had ulcers in the ascending aorta and were excluded from this analysis. In 16 cases intramural hematoma was identified at angiography by examining the aortic profile against the background lung tissue on the left side of the aorta with a wall thickness greater than $5 \mathrm{~mm}$ considered diagnostic. ${ }^{7}$ The diagnostic criteria of IMH by $\mathrm{CT}$ scanning included asymmetric wall thickening greater that $3 \mathrm{~mm}$ as determined by medial displacement of intimal calcification or the presence of high density, indicating hematoma in the acute setting. The medical records of confirmed cases of PAU with or without IMH were reviewed for clinical presentation and inhospital course. All subsequent imaging studies were examined for evolution of the lesion. Late follow-up was obtained by chart review, search of the social security death index, and telephone interview. Death certificates were obtained whenever possible (16 cases) to determine cause of death. Follow-up information was available in $90 \%$ of patients within the last 5 years and $88 \%$ of patients within the last 3 years.

The ulcer location was recorded as involving the aortic arch or the proximal, middle, or distal third of the descending thoracic aorta. Ulcer dimensions were measured according to maximum depth from the lumen into the aortic wall, maximum width at entry site from the lumen, and maximum length of the intramural component of the ulcer itself (Figure 1). Intramural hematoma confined to 2 or fewer of these segments was defined as localized, whereas those involving more than 2 segments were defined as extensive.

Data are expressed as mean \pm standard deviation or as proportions. Univariate analysis was performed on all clinical and radiological measurements with $\chi^{2}$ test used for categorical variables and unpaired Student $t$ test used for continuous variables. Multivariate logistic regression analysis was carried out using variables significant by univariate analysis and those suspected on clinical grounds. Survival was estimated and compared by Kaplan-Meier analysis with log-rank test.

\section{Results}

The study group was characterized by advanced age, with hypertension almost universal and tobacco abuse common (Table 1). Most patients were symptomatic on presentation, typically with back pain. Asymptomatic ulcers were identified during the course of evaluation of an abnormal chest radiograph in 11 , evaluation of other aneurysmal disease in 6 , and incidental to the evaluation of other intrathoracic (n $=6)$ or extrathoracic $(n=2)$ pathology.

Approximately equal proportions of the medical and surgical groups were symptomatic upon presentation. Aortic pathology was similar in both medically and surgically treated patients (Table 2). Most ulcers were associated with an IMH, slightly over half of which were localized in extent. Patients going to surgery tended to have only slightly larger aortic diameter than those treated medically.

Over the course of the study interval almost one-third of patients underwent surgery, although this evolved over time with 19 of $31(61 \%)$ treated surgically between 1977 and 1990 and 10 of 74 (14\%) treated surgically since 1991. Cited indications for surgery included known or suspected rupture in 9 patients, refractory pain in 5, and increasing aortic size in 4 . Three additional patients underwent surgery because involvement of the arch was judged by the treating physicians at the time to be an indication for surgery and another 3 early in the experience when presence of an ulcer was felt to be an indication. One patient underwent surgery because of acute paraplegia, the only instance of branch vessel occlusion recognized, and 1 for mycotic involvement of the ulcer. Of 73 patients who survived the initial nonoperative management, 6 underwent late surgery for enlarging aneurysm and 2 for ruptured abdominal aortic aneurysm.

Early mortality was $4 \%$ in the medically treated patients and $21 \%$ for the surgical group (Table 3 ). Surgical mortality increased in the latter part of the series ( 4 of 10 between 
TABLE 1. Patient profiles

\begin{tabular}{|c|c|c|c|c|}
\hline Variables & $\begin{array}{l}\text { Medical } \\
(n=76)\end{array}$ & $\begin{array}{l}\text { Surgical } \\
(n=29)\end{array}$ & $P$ value & $\begin{array}{c}\text { Total } \\
(n=105)\end{array}$ \\
\hline Age (y) & $72 \pm 9$ & $72 \pm 7$ & NS & $72 \pm 9$ \\
\hline Gender (M:F) & $51: 25$ & $22: 7$ & NS & $73: 32$ \\
\hline \multicolumn{5}{|l|}{ Comorbidities } \\
\hline Hypertension & $70(92 \%)$ & $27(93 \%)$ & NS & $97(92 \%)$ \\
\hline Tobacco use & $58(76 \%)$ & $23(79 \%)$ & NS & $81(77 \%)$ \\
\hline COPD & $19(25 \%)$ & $6(219 \%)$ & NS & $25(24 \%)$ \\
\hline CAD & $35(46 \%)$ & $13(45 \%)$ & NS & $48(46 \%)$ \\
\hline Renal dysfunction & $16(21 \%)$ & $6(21 \%)$ & NS & $22(21 \%)$ \\
\hline AAA & $46(61 \%)$ & $18(62 \%)$ & NS & $64(61 \%)$ \\
\hline Symptomatic & $56(74 \%)$ & $23(79 \%)$ & NS & $79(75 \%)$ \\
\hline Pleural effusion & $21(28 \%)$ & $11(38 \%)$ & NS & $32(30 \%)$ \\
\hline Rupture & $2(3 \%)$ & $7(24 \%)$ & $<.001$ & $9(9 \%)$ \\
\hline
\end{tabular}

$C O P D$, Chronic obstructive pulmonary disease; $C A D$, coronary artery disease; $A A A$, abdominal aortic aneurysm; $N S$, not significant. Renal dysfunction is defined as serum creatinine level greater than $1.5 \mathrm{mg} / \mathrm{dL}$.

TABLE 2. Characteristics of the aortic pathology

\begin{tabular}{|c|c|c|c|c|}
\hline Variables & $\begin{array}{l}\text { Medical } \\
(n=76)\end{array}$ & $\begin{array}{l}\text { Surgical } \\
(n=29)\end{array}$ & $P$ value & $\begin{array}{c}\text { Total } \\
(\mathrm{n}=105)\end{array}$ \\
\hline \multicolumn{5}{|l|}{ Location of PAU } \\
\hline Arch & $8(11 \%)$ & $1(3 \%)$ & NS & $9(11 \%)$ \\
\hline Descending & $71(93 \%)$ & $28(97 \%)$ & NS & $99(94 \%)$ \\
\hline Multiple & $9(12 \%)$ & $2(7 \%)$ & NS & $11(10 \%)$ \\
\hline Maximum aortic diameter (mm) & $42.4 \pm 7.7$ & $47.2 \pm 8.1$ & .09 & $43.4 \pm 7.9$ \\
\hline Presence of IMH & $59(78 \%)$ & $26(90 \%)$ & NS & $85(81 \%)$ \\
\hline Maximum thickness of IMH (mm) & $9.9 \pm 4.4$ & $9.2 \pm 2.5$ & NS & $9.7 \pm 4.0$ \\
\hline \multicolumn{5}{|l|}{ Location of IMH* } \\
\hline Ascending & $4(7 \%)$ & $1(4 \%)$ & NS & $5(6 \%)$ \\
\hline Arch & $14(24 \%)$ & $3(12 \%)$ & NS & $17(20 \%)$ \\
\hline Descending & $57(97 \%)$ & $26(100 \%)$ & NS & $83(98 \%)$ \\
\hline Localized IMH* & $35(59 \%)$ & $14(54 \%)$ & NS & $49(58 \%)$ \\
\hline
\end{tabular}

$P A U$, Penetrating atherosclerotic ulcer; $I M H$, intramural hematoma.

*Of the patients with IMH.

1990 and 2002), likely reflecting more selective criteria for surgery with only those failing medical therapy proceeding to operation. Late survival is depicted in Figure 2 with a median follow-up interval of 45.6 months (range 1-189) among medically treated patients and 29.0 months (range 1-187) for surgical patients. Causes of late death were known to be related to the aorta in 3 surgical patients and 5 medical patients. There were 4 deaths due to unknown cause in the surgical group and 11 in the medical group. If these deaths are attributed to the aorta, the incidence of late death due to aortic disease in the surgical group would be 7 of 23 or $30 \%$ as compared with 15 of 73 or $21 \%$ in the medical group.

A comparison of the aortic pathology in symptomatic and asymptomatic patients is presented in Table 4. Pleural effusion, extensive IMH, and rupture were more common among symptomatic patients possibly evidencing "active" disease. Ulcer dimensions were greater among asymptom-
TABLE 3. Causes of early (30-d) and late mortality

\begin{tabular}{lc}
\hline Surgical & Medical \\
\hline $\begin{array}{c}\text { Early }(\mathrm{n}=6 / 29,20.7 \%) \\
\text { Intraoperative cardiac }\end{array}$ & Early $(\mathrm{n}=3 / 76,3.9 \%)$ \\
arrest (2) & Rupture (patient refused \\
Stroke (2) & Rupture of hepatic artery \\
& aneurysm (1) \\
Multiorgan failure (1) & Sepsis after other surgery (1) \\
Bleeding (1) & \\
Late (n = 18/23, 78\%) & Late (n = 30/73, 42\%) \\
Aorta-related (3) & Aorta-related (5) \\
Other cardiovascular (7) & Other cardiovascular (9) \\
Noncardiovascular (4) & Noncardiovascular (5) \\
Unknown (4) & Unknown (11) \\
\hline
\end{tabular}

$P<.05$, surgical vs medical.

atic than symptomatic patients, perhaps reflecting a more chronic process, although this is speculative. Of particular 

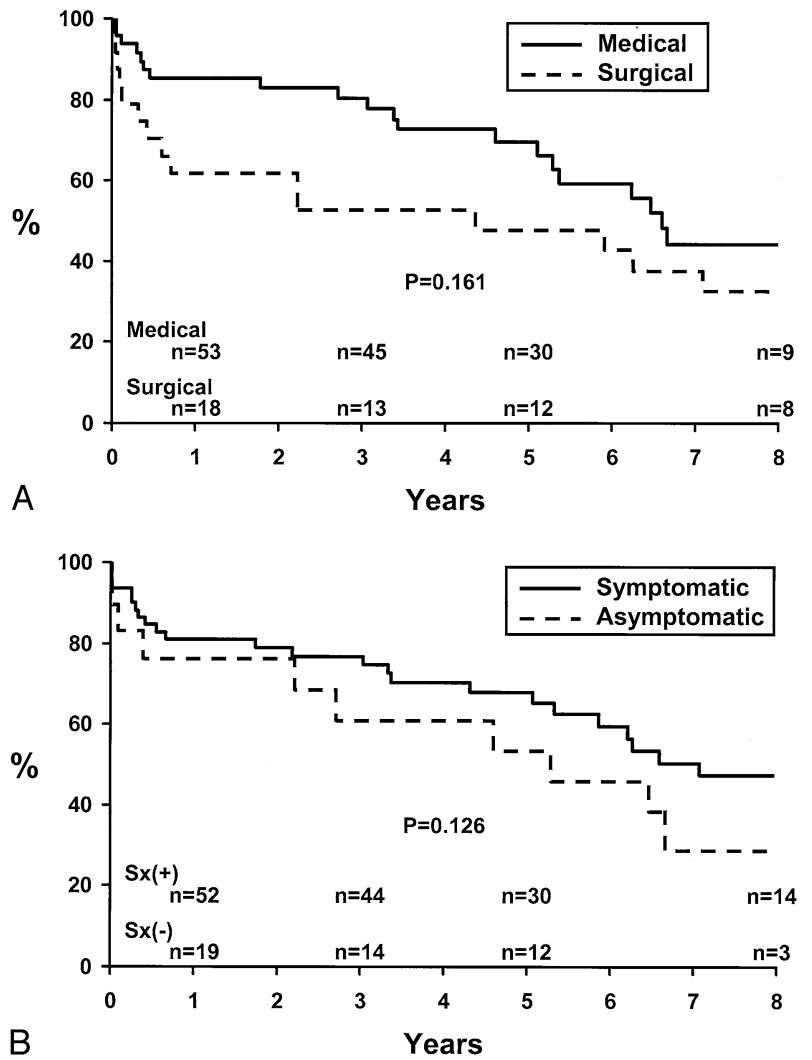

Figure 2. A, Actuarial survival of medically (median follow-up 45.6 months, range 1-187) and surgically (median follow-up 29.0 months, range 1-187) treated patients (median follow-up). $P=.25$ by log-rank test. B, Actuarial survival of patients presenting with symptomatic (median follow-up 43.6 months, range 1-187) versus asymptomatic (median follow-up 48.5 months, range 1-189) ulcers. $P=.15$ by log-rank test.

TABLE 4. Comparison of symptomatic versus asymptomatic cases

\begin{tabular}{lccc}
\hline Variables & $\begin{array}{c}\text { Symptomatic } \\
(\mathbf{n}=\mathbf{7 9})\end{array}$ & $\begin{array}{c}\text { Asymptomatic } \\
(\mathbf{n}=\mathbf{2 6})\end{array}$ & $\boldsymbol{P}$ value \\
\hline Arch ulcer & $4(5 \%)$ & $5(19 \%)$ & .03 \\
Pleural effusion & $29(37 \%)$ & $3(12 \%)$ & .02 \\
AAA & $42(53 \%)$ & $22(85 \%)$ & $<.01$ \\
Extensive IMH & $32(54 \%)$ & $4(15 \%)$ & NS \\
Rupture & $8(10 \%)$ & $1(4 \%)$ & NS \\
Aortic diameter (mm) & $42.7 \pm 8.0$ & $44.9 \pm 7.8$ & NS \\
Thickness of IMH (mm) & $9.2 \pm 3.6$ & $11.8 \pm 5.3$ & NS \\
Dimension of ulcer & & & \\
$\quad$ Depth (mm) & $10.0 \pm 8.2$ & $12.9 \pm 6.9$ & .01 \\
$\quad$ Width (mm) & $13.9 \pm 13.8$ & $18.5 \pm 10.9$ & .02 \\
$\quad$ Length (mm) & $15.7 \pm 17.5$ & $19.4 \pm 13.0$ & .05 \\
Surgery & $23(29 \%)$ & $6(23 \%)$ & NS \\
30-d mortality & $6(8 \%)$ & $3(12 \%)$ & NS \\
\hline IMH, Intramural hematoma; & $A A A$, abdominal aortic aneurysm; NS, not \\
significant. & & &
\end{tabular}

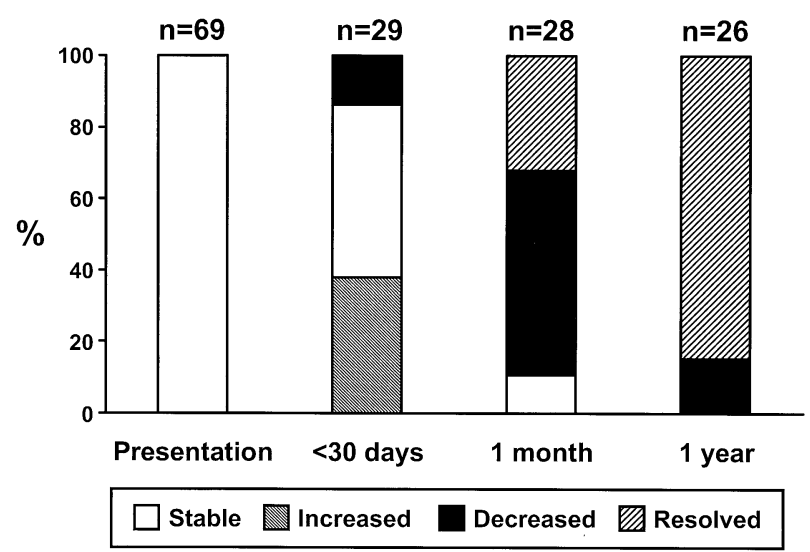

Figure 3. Fate of intramural hematomas among patients with serial computerized tomographic studies.

note, the rate of surgical intervention was similar among symptomatic and asymptomatic patients, as was the 30-day mortality. Late outcome of symptomatic and asymptomatic patients was remarkably similar as well, as shown in Figure 2, $B$.

The fate of the intramural hematoma is depicted in Figure 3. Of 58 medical patients, serial CT imaging studies permitting quantitative comparison of the IMH were available in 40 (70\%). Among these, for scans taken within 30 days of diagnosis, slightly over one-third of the hematomas demonstrated increase in size and a somewhat larger percentage demonstrated stability. For those scans obtained at approximately 1 month, over one-third demonstrated resolution of the IMH and $10 \%$ stability with the remainder having demonstrated a decrease. By 1 year the vast majority of intramural hematomas had resolved.

A significant number of patients demonstrated progression of their ulcer to saccular aneurysm in follow-up. We distinguish giant ulcer from saccular aneurysm on the basis of the presence of overhanging edges and shelflike borders, with the adjacent aortic lumen characterizing the former and the latter having a seamless transition from sac to adjacent aortic lumen. Among 54 PAU patients with serial scans, 26 developed an asymmetrical aneurysm. Of these, 5 underwent late surgery without mortality. The remainder have not reached size criteria for repair or the patients have declined operation.

In an effort to evaluate the validity of a treatment algorithm beginning with medical stabilization, we analyzed the study group by defining failure of medical therapy as ulcerrelated death or surgical intervention. Such an approach is inherently limited as not all surgical patients were true medical failures given the aggressive approach undertaken in the early years. Simple comparison of the outcome of medical and surgical groups, however, is more gravely flawed by selection bias with the most ill patients typically 
TABLE 5. Predictor for failure of medical therapy (early surgery or death)

\begin{tabular}{|c|c|c|c|c|c|c|}
\hline \multicolumn{4}{|l|}{ Univariate analysis } & \multicolumn{3}{|c|}{ Multivariate analysis } \\
\hline Variables & $\begin{array}{l}\text { Success } \\
(\mathrm{n}=75)\end{array}$ & $\begin{array}{l}\text { Failure } \\
(n=30)\end{array}$ & $P$ value & Variables & $P$ value & $\begin{array}{l}\text { Odds } \\
\text { ratio }\end{array}$ \\
\hline Female & $25(33 \%)$ & $7(23 \%)$ & NS & Rupture & .01 & 20.45 \\
\hline Age & $72 \pm 9$ & $72 \pm 7$ & NS & Time of diagnosis $(<1990)$ & $<.001$ & 9.90 \\
\hline Symptomatic & $55(73 \%)$ & $24(80 \%)$ & NS & & & \\
\hline AAA & $46(61 \%)$ & $18(60 \%)$ & NS & & & \\
\hline Pleural effusion & $21(28 \%)$ & $11(37 \%)$ & NS & & & \\
\hline Rupture & $1(1 \%)$ & $8(27 \%)$ & $<.01$ & & & \\
\hline Arch ulcer & $8(11 \%)$ & $1(3 \%)$ & NS & & & \\
\hline Max aorta (mm) & $42.4 \pm 7.7$ & $47.2 \pm 8.1$ & NS & & & \\
\hline Ulcer depth (mm) & $10.5 \pm 8.2$ & $11.1 \pm 7.4$ & NS & & & \\
\hline Ulcer width (mm) & $14.9 \pm 14.3$ & $15.1 \pm 10.0$ & NS & & & \\
\hline Ulcer length (mm) & $14.9 \pm 14.6$ & $21.0 \pm 20.7$ & NS & & & \\
\hline Time at diagnosis $(<1990)$ & $12(16 \%)$ & $19(63 \%)$ & $<.001$ & & & \\
\hline
\end{tabular}

$\overline{A A A}$, Abdominal aortic aneurysm; Max aorta, maximum aortic diameter. When aortic diameter was removed from analysis, rupture and time at diagnosis were significant predictors for adverse clinical outcomes.

${ }^{*}$ Aortic diameter was only available in $57 \%$ of patients as a number of these diagnoses were made on the basis of angiograms that lacked available scales for measurement.

proceeding to the surgical group. As shown in Table 5, only rupture on admission and diagnosis before 1990 predicted surgery or death due to the aorta. Maximum aortic diameter, ulcer dimensions, symptomatic status, and pleural effusion did not predict failure of medical therapy. Of note, however, aortic diameter was only available in $57 \%$ of patients as a number of these diagnoses were made on the basis of angiograms or early CT scans that lacked appropriate scales. When aortic diameter was incorporated within a multivariate model, only rupture was a significant predictor. When aortic diameter was removed from analysis, rupture and surgery before 1990 were significant predictors.

In an effort to control for referral bias, we analyzed the subgroup of patients residing within 100 miles of our institution. Within that radius, 14 other hospitals perform cardiovascular surgery, 10 of which are in the Twin Cities of Minneapolis and St Paul. Few patients are referred from Minneapolis-St Paul given tertiary care centers in that community; however, apart from that population center it is likely that our experience represents a significant percentage of the individuals diagnosed with this entity in our region with little selection bias. As shown in Table 6, the regional subgroup was similar to the whole group apart from the lower frequency of asymptomatic status. One might anticipate a higher incidence of incidentally identified ulcers among patients traveling from a distance to undergo diagnostic evaluation of other conditions. There was, however, no significant difference in rupture, distribution of ulcers, ulcer dimensions, incidence of surgery, or early mortality.

\section{Discussion}

The results of this study indicate that a substantial number of patients with PAU can be treated nonoperatively in the
TABLE 6. Comparison of regional (within 100 miles) and total cases

\begin{tabular}{lcc}
\hline Variables & $\begin{array}{c}\text { Regional } \\
\text { (n= 56) }\end{array}$ & $\begin{array}{c}\text { Total } \\
\text { (n= 105) }\end{array}$ \\
\hline Symptomatic & $50(89 \%)$ & $79(75 \%)$ \\
Pleural effusion & $19(34 \%)$ & $32(30 \%)$ \\
Arch ulcers & $3(5 \%)$ & $9(9 \%)$ \\
Rupture & $7(13 \%)$ & $9(9 \%)$ \\
Surgery & $14(25 \%)$ & $29(28 \%)$ \\
Maximum aortic diameter & $41.6 \pm 7.3$ & $43.4 \pm 8.0$ \\
$\quad$ (mm) & & \\
Ulcer dimension & & \\
$\quad$ Depth (mm) & $8.3 \pm 5.7$ & $10.7 \pm 8.0$ \\
$\quad$ Width (mm) & $11.2 \pm 6.7$ & $15.0 \pm 13.3$ \\
$\quad$ Length (mm) & $13.8 \pm 15.5$ & $16.5 \pm 16.6$ \\
Mortality & $3(5 \%)$ & $9(9 \%)$ \\
\hline
\end{tabular}

acute setting. Given the high frequency of comorbid conditions in these elderly patients, an expectant approach is reasonable. The majority of IMH when managed medically appear to resolve with time, and the risk of acute death during the index hospitalization among medically treated patients appears low. This is not to say that this condition can be treated casually. There is risk of late development of a saccular aneurysm, and a significant number of patients require early or late operation. Approximately one-third of individuals in our study underwent early or late operation, although this rate is likely inflated somewhat by our aggressive approach to operation for this entity early in our experience. Given the retrospective nature of the data set, one cannot predict the outcome had all patients been treated expectantly. In the last decade, however, in which the op- 
erative rate was much lower than the previous rate, the early mortality rate among medically treated patients remained low at $3 \%$ and the surgical mortality was $40 \%$.

Late mortality in this patient group was high, as was surgical mortality. We believe that both reflect the comorbidities typically present in the patients in whom PAU are most often seen. The high rate of late cardiovascular death due to causes other than aneurysmal disease supports this hypothesis. Surgical mortality was high, likely for the same reason, and has in fact increased due to adverse selection as surgery is reserved for only the most ill patients. Of particular note, while the late survival data is limited by incomplete knowledge of the causes of late death, late survival curves were of similar shape in both the surgical and medical groups, suggesting that early surgery did not protect these individuals.

Long-term follow-up of these individuals is important. In our opinion these patients should be cared for by individuals with particular interest in the entity. The value of betablockade to improve long-term outcome in patients with IMH has been convincingly demonstrated. ${ }^{3}$ At a minimum these results can be applied to patients with PAU and IMH and, we believe, likely to those with PAU without IMH as well. Patients with PAU have previously been shown to be at ongoing risk of development of late pseudoaneurysm, rupture, or dissection ${ }^{11,13,14}$ and accordingly should be monitored closely by appropriate specialists. The advent of endovascular stent grafts ${ }^{15-17}$ offers yet another option in the management of these complex patients and highlights the importance of a multidisciplinary approach to their care. It should also be noted that the use of these devices entails early and late risks, and their application should be directed by a sophisticated understanding of the natural history of these conditions.

We were unable to identify useful predictors of clinical behavior of the aortic pathology. Only rupture was a predictor of surgery or death due to the aortic disease. In a previous analysis restricted to those PAU complicated by IMH, maximum aortic diameter did reach statistical significance with a $P$ value of .03 but an odds ratio of only 1.13 (data not shown). In analysis of the entire group including those PAU without IMH, there was a statistically insignificant trend toward larger aortic diameter in the surgical group than medical group; however, these data were only available in $57 \%$ of cases. Others, however, have data suggesting that maximum aortic diameter may be a useful indicator of clinical behavior. ${ }^{18-20}$ Curiously, in 1 recent study, smaller aortic diameter was associated with progression. ${ }^{3}$ Our study also did not identify ulcer size as a predictor of progression as suggested by others. ${ }^{12}$ In our opinion these conflicting results reflect the limitations of what remain relatively small data sets. Intriguingly, in our study, neither the symptomatic status of patients nor the presence of an IMH appeared to be a useful indicator. The number of ulcers involving the aortic arch was small, and our study did not identify location of either ulcer or hematoma as predictive of outcome. Similarly the extent of the intramural hematoma did not predict outcome. The subject clearly warrants further study.

Our recommendations for clinical management are somewhat at variance with those of Coady and colleagues 9 and Tittle and colleagues. ${ }^{11}$ Although we agree that this is a high-risk subset of patients, we advocate a more expectant approach in their management. This may in part be due to differences in patient populations, with selection bias favoring referral of the most gravely and acutely ill to a quaternary facility in an area of high population density while more stable patients remain in regional facilities. Although our institution is a referral center as well, we have a large regional practice with few competing sites outside of the Twin Cities performing cardiac surgery. Our data set, therefore, may be more representative of the condition as observed in the community. It should be noted as well that nonoperative management of IMH, particularly involving the descending thoracic aorta, has been advocated previously by others ${ }^{10,21,22}$ and resolution of IMH has also been reported. ${ }^{19}$ Recently some authors have even suggested that IMH involving the ascending aorta might be treated nonoperatively. ${ }^{23}$ Our data do not address this issue, and we do not endorse this approach. However, the level of controversy over management of acute aortic syndromes should be emphasized.

Without question, significant limitations of our study must be recognized. Although it represents a 25 -year experience and a large number of cases relative to those previously reported in the literature, numbers are still small, making statistical analyses difficult. Recently this problem has been addressed via meta-analysis ${ }^{22}$; however, this approach is subject to profound reporting bias. Incomplete follow-up imaging scans as well as incomplete long-term clinical follow-up and knowledge of the cause of death are further limitations our study shares with many others in the literature. Despite these limitations we feel that these data support expectant therapy of these difficult lesions, which most often occur in a complex patient population.

\section{References}

1. Vilacosta I, Roman JA. Acute aortic syndrome. Heart (British Cardiac Society). 2001;85:365-8.

2. Lui RC, Menkis AH, McKenzie FN. Aortic dissection without intimal rupture: diagnosis and management. Ann Thorac Surg. 1992;53:886-8.

3. von Kodolitsch Y, Csosz SK, Koschyk DH, et al. Intramural hematoma of the aorta: predictors of progression to dissection and rupture. Circulation. 2003;107:1158-63.

4. Sohn DW, Jung JW, Oh BH, et al. Should ascending aortic intramural hematoma be treated surgically? Am J Cardiol. 2001;87:1024-6.

5. Song JK, Kim HS, Kang DH, et al. Different clinical features of aortic intramural hematoma versus dissection involving the ascending aorta (comment). J Am Coll Cardiol. 2001;37:1604-10. 
6. Song JK, Kim HS, Song JM, et al. Outcomes of medically treated patients with aortic intramural hematoma (comment). Am J Med. 2002;113:181-7.

7. Stanson AW, Kazmier FJ, Hollier LH, et al. Penetrating atherosclerotic ulcers of the thoracic aorta: natural history and clinicopathologic correlations. Ann Vasc Surg. 1986;1:15-23.

8. Hussain S, Glover JL, Bree R, Bendick PJ. Penetrating atherosclerotic ulcers of the thoracic aorta. J Vasc Surg. 1989;9:710-7.

9. Coady MA, Rizzo JA, Hammond GL, et al. Penetrating ulcer of the thoracic aorta: what is it? How do we recognize it? How do we manage it? J Vasc Surg. 1998;27:1006-15 (discussion 1015-6).

10. Robbins RC, McManus RP, Mitchell RS, et al. Management of patients with intramural hematoma of the thoracic aorta. Circulation. 1993;88:II1-10.

11. Tittle SL, Lynch RJ, Cole PE, et al. Midterm follow-up of penetrating ulcer and intramural hematoma of the aorta. $J$ Thorac Cardiovasc Surg. 2002;123:1051-9.

12. Ganaha F, Miller DC, Sugimoto K, et al. Prognosis of aortic intramural hematoma with and without penetrating atherosclerotic ulcer: a clinical and radiological analysis (comment). Circulation. 2002;106:342-8.

13. Ando Y, Minami H, Muramoto H, et al. Rupture of thoracic aorta caused by penetrating aortic ulcer. Chest. 1994;106:624-6.

14. Cooke JP, Kazmier FJ, Orszulak TA. The penetrating aortic ulcer: pathologic manifestations, diagnosis, and management. Mayo Clin Proc. 1988;63:718-25.

15. Dake MD, Miller DC, Mitchell RS, et al. The "first generation" of endovascular stent-grafts for patients with aneurysms of the descending thoracic aorta. J Thorac Cardiovasc Surg. 1998;116:689-703 (discussion 703-4).

16. Eggebrecht H, Baumgart D, Schmermund A, et al. Endovascular stent-graft repair for penetrating atherosclerotic ulcer of the descending aorta. Am J Cardiol. 2003;91:1150-3.

17. Grabenwoger M, Fleck T, Czerny M, et al. Endovascular stent graft placement in patients with acute thoracic aortic syndromes. Eur J Cardiothorac Surg. 2003;23:788-93 (discussion 793).

18. Kaji S, Nishigami K, Akasaka T, et al. Prediction of progression or regression of type A aortic intramural hematoma by computed tomography. Circulation. 1999;100:II281-6.

19. Nishigami K, Tsuchiya T, Shono H, et al. Disappearance of aortic intramural hematoma and its significance to the prognosis. Circulation. 2000;102(Suppl 3):III243-7.

20. Sueyoshi E, Imada T, Sakamoto I, et al. Analysis of predictive factors for progression of type B aortic intramural hematoma with computed tomography (comment). J Vasc Surg. 2002;35:1179-83.

21. Muluk SC, Kaufman JA, Torchiana DF, et al. Diagnosis and treatment of thoracic aortic intramural hematoma. J Vasc Surg. 1996;24:1022-9.

22. Maraj R, Rerkpattanapipat P, Jacobs LE, et al. Meta-analysis of 143 reported cases of aortic intramural hematoma. Am J Cardiol. 2000;86: 664-8.

23. Moizumi Y, Komatsu T, Motoyoshi N, Tabayashi K. Management of patients with intramural hematoma involving the ascending aorta (comment). J Thorac Cardiovasc Surg. 2002;124:918-24.

\section{Discussion}

Dr John A. Elefteriades (New Haven, Conn). I would like to congratulate the authors on a very important contribution to this topic. Because these are new diseases of the current era of CT, magnetic resonance imaging, and transesophageal echocardiographic imaging, our understanding of their pathophysiology, natural behavior, and optimal treatment are incomplete, and this important paper helps us to understand these entities better.

I have a number of questions for Dr Cho. First, I would like to ask you about definitions. In the text, you indicate that nearly half of your cases were diagnosed by angiography alone. This reflects the 25-year time span of your review. How could you make a diagnosis of intramural hematoma based on an angiogram? Also, I wonder, why did you exclude ulcers without intramural hema- toma from your study group, and if you included them, does the behavior become more benign or more malignant?

Next, I would like to ask you about the acuity of presentation. You did not exclude ulcers presenting as incidental findings in patients who are well without an acute aortic syndrome. What are the rates of malignant behavior if those patients with only incidental findings are excluded?

And then I would like to ask you about your management recommendations. In particular, you state that most cases can be managed nonoperatively in the acute setting, yet one-third of your patients had serious early complications requiring immediate operation and nearly $20 \%$ of the patients died in midterm follow-up. These data reflect a serious condition with quite a dismal prognosis. Do you think we should be cautious in communicating to the audience any message of benignity regarding the behavior of these lesions?

And then I would like to ask you a few brief questions about the general aspects of these conditions that may be interesting to the audience.

As you can see in that picture there, these lesions look exactly like duodenal ulcers, and I wonder what your thoughts are about the etiology of these conditions. We have looked diligently for pathogens, including Helicobacter, and we have not found them. An obvious question is, have you ever considered stent grafting for these lesions?

And finally, I would like to ask you about branch vessel occlusion. In our experience, these lesions, in contradistinction to typical aortic dissection, never produce a branch vessel occlusion. Did you indeed identify any ischemic vascular complications in your series of patients?

Dr Sundt. Thank you, Dr Elefteriades. There is a symmetry to this that some may appreciate. A few years ago I had the privilege of discussing Dr Elefteriades' series in this forum, and it just goes to show you that what goes around comes around. So be careful what you ask people, they may come back and ask you the same thing. It is a good rule in life, I suppose.

This is an exciting time in the treatment I think of aortic disease because, thanks to series like those that John has accumulated and the one I hope that we have contributed to the literature here, we can actually move from anecdote to evidence. Up to this point, the majority of literature concerning these entities have really had just a handful of patients in any particular subgroup.

You asked about definitions, specifically the definition at angiography of intramural hematoma. We relied very much on Dr Stanson, who was our radiologist in this endeavor and was the individual who originally described this entity in 1986, and Dr Cho and Dr Stanson spent many hours reviewing each and every one of these studies. The CT and magnetic resonance criteria were presence of an ulcer and thickening of the wall greater than $3 \mathrm{~mm}$ and by angiography, and it is a challenge to make this diagnosis by angiography. Dr Stanson required a thickening of the wall apparent by angiography of at least $5 \mathrm{~mm}$.

For the question about excluding penetrating ulcers without intramural hematomas, this is another issue concerning these entities and is reminiscent of Craig Miller's comment yesterday about apples and oranges: it sort of depends on whether you are a lumper or a splitter. How are you going to divide up these entities? Do intramural hematomas with ulcers behave differently than 
intramural hematomas without, and conversely, are there differences in behavior for ulcers with and without hematoma?

We have thought of this particular entity of intramural hematoma predominantly as a condition that reflects disease of the media and of ulcers as a condition that reflects disease of the intima. And I think that at least as a first pass we ought to try and focus on each of these entities in the different quadrants defined by these axes of disease. So that is why we focused on this particular area, although it does not appear to yield significantly different results if you look at penetrating ulcers without intramural hematoma. They appear to behave in a very similar way, at least at first pass.

What about asymptomatic ulcers with hematomas and do they behave differently, those that were identified incidentally? In fact it appears that they behave in a very similar way. So at least at this point with still very small numbers we cannot tease out subgroups that behave particularly badly or particularly well, which comes to the issue of recommendations. And I agree with you, I don't think the message is that you can forget about them.

These people ought to be followed carefully. They ought to be followed by individuals with interest in aortic disease, which is to say that in my opinion they should not be given up to the cardiologists in the cardiac care unit who are really more interested in acute myocardial infarction than they are in aortic disease.

Someone, whether it is a cardiologist or a surgeon with interest in aortic disease, ought to follow these patients and that is how we will get the best long-term results with this.

I agree that it requires judgment, and I think that that is the take-home lesson to this is that it is not a knee-jerk reflex that they need to be operated on and it is not a knee-jerk reflex that they can be treated nonoperatively. We still need to exercise surgical judgment.

With regard to the etiology, I don't know the etiology of it apart from this concept that it is a disease of the intima, and I am very intrigued by your notion that they may be related to having an infectious etiology.

Stent grafting again relates to what their long-term behavior is. If in fact they have a relatively benign behavior or if there is a subgroup that has relatively benign behavior, then I don't think we should be deploying stent grafts willy-nilly in all of these aortas. These are old, fragile patients; they are going to have complications related to groin cannulation to pass these stent grafts. They are really not people that you want to touch, if you can help it.

We have not seen branch vessel occlusion, as was your experience. This does not appear to be a component of this entity.

Dr Irving L. Kron (Charlottesville, $\mathrm{Va}$ ). Dr Sundt, this is a wonderful contribution. These are often ancient patients, as you all know, and you hate to even start an intravenous line on them, let alone an aortic operation.

My question is specific to the arch. You mentioned there was no difference in terms of acuteness and what you did. What about late term? And more importantly, though you didn't speak of this, I am sure it is in your review at Mayo Clinic, what about the hematoma of the ascending aorta? We now consider that a surgical indication. Can you shed some more light on that? Thank you.

Dr Sundt. To directly answer your question, the reason I think that location didn't come out as a predictor is that the numbers of ulcers and hematomas in the ascending aorta and arch were very small, which brings to light an interesting point as one reads the literature, perhaps 1 of the reasons that people come up with different recommendations is that as you go from 1 series to another, there can be a very marked difference in distribution. So in a series that shows $50 \%$ of the ulcers and hematomas to be in the ascending aorta, it is not surprising to me that they find a natural history rather than another series that is published that has $2 \%$ in the ascending aorta or in the arch. I think we need to be precise about those definitions.

I think that all of us at Mayo would agree that we tend to be very aggressive with ascending aortas. I think that the operative risk is probably less for a tube graft of the ascending aorta than it is management of an arch lesion or a descending thoracic aorta. The arch is difficult because one would think logically that those would be "bad actors."

Again, we don't have enough data to speak of that, but, as you said, these are often ancient patients with extensive atherosclerotic disease, and the prospect of an arch replacement in them is not very appealing. So I don't know what to say about the arch other than to use judgment. If one feels that one can do an arch replacement at reasonable risk, that is certainly a reasonable thing to do, but I don't think that the mere presence of an ulcer in the arch mandates immediate surgical intervention.

Dr Lars G. Svensson (Cleveland, Ohio). Dr Sundt, I would like to congratulate you and your group at Mayo Clinic for bringing to us this big study with a large series of patients. I should point out that $\mathrm{Dr}$ Shannon Shumacker actually described the entity, although there was a period when there wasn't much written about it.

One of the things we noticed in the 1980s and 1990s in treating these patients medically as type III DeBakey dissections was that a number of them ruptured. We then did postmortem studies on them and found that the plane of dissection or the hematoma is different than the classic dissections and that it is not in the media but between the media and the adventitia. I think that is why we see more pleural effusions and why we see perhaps more often patients rupturing, as some of the data from Yale would also suggest. So we have adopted a more aggressive approach and we routinely now stent these patients, and we have had good results. There are some papers coming out showing good results.

I certainly would encourage you to be more aggressive in treating them in the acute situation when they present with a hematoma, and including obviously, as Dr Kron has pointed out, the patients with ascending and arch hematomas.

As I recall, you do a lot of autopsies at the Mayo Clinic. Did you look at the plane of dissection in these patients who may have died?

Dr Sundt. We have not tapped those effusions, and in fact, as far as we could tell from this analysis, the presence of an effusion didn't predict behavior either.

Dr Robert Dion (Leiden, The Netherlands). I would like to ask you, in the presence of pleural effusion, what is your rationale? Are you going in all the time or are you puncturing to see if it is blood or reactive fluids? What is your position when you have a patient who is quite stable hemodynamically and has pain and pleural effusion, what are you doing?

Dr Sundt. We have not tapped those effusions, and in fact, as far as we could tell from this analysis, the presence of an effusion didn't predict behavior either. 
Dr Tirone E. David (Toronto, Ontario, Canada). Thor, why don't you stent them once the diagnosis is made? If $90 \%$ to $95 \%$ are located in the proximal descending thoracic aorta, this is a perfect place to deploy a stent. It doesn't matter whether the patient is 90 or 60 years old.
Dr Sundt. I think that deploying a stent is not a zero-risk proposition. There are all kinds of groin complications that occur with them, or can occur with them. That is a theoretical issue. There is a very practical issue as well, which is that we don't have a thoracic stent graft.

Access to The Journal of Thoracic and Cardiovascular Surgery Online is reserved for print subscribers!

Full-text access to The Journal of Thoracic and Cardiovascular Surgery Online is available for all print subscribers. To activate your individual online subscription, please visit The Journal of Thoracic and Cardiovascular Surgery Online, point your browser to http://www.mosby.com/itcvs, follow the prompts to activate your online access, and follow the instructions. To activate your account, you will need your subscriber account number, which you can find on your mailing label (note: the number of digits in your subscriber account number varies from 6 to 10). See the example below in which the subscriber account number has been circled:

\section{Sample mailing label}

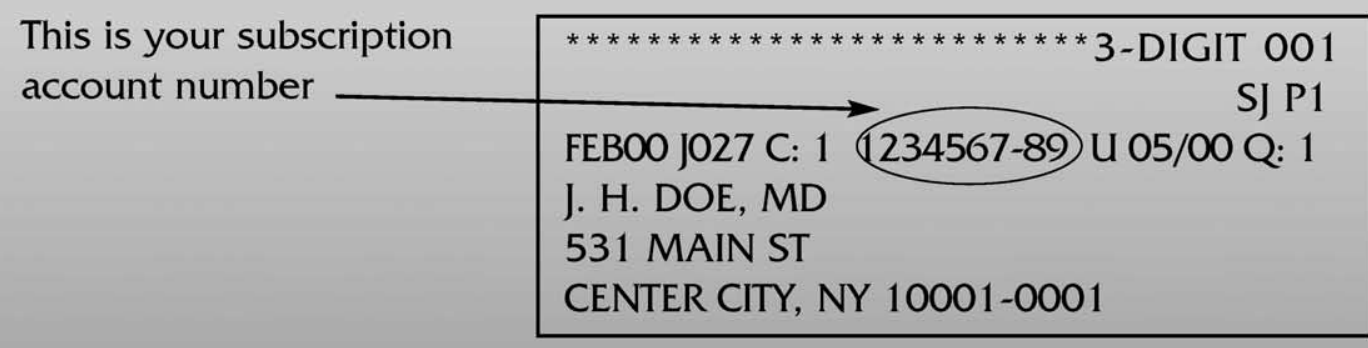

Personal subscriptions to The Journal of Thoracic and Cardiovascular Surgery Online are for individual use only and may not be transferred. Use of The Journal of Thoracic and Cardiovascular Surgery Online is subject to agreement to the terms and conditions as indicated online. 